\title{
CARACTERIZAÇÃO DA PRODUÇÃO DE GENÓTIPOS DE BANANA INTRODUZIDOS NA REGIÃO DE BONITO - MS ${ }^{1}$
}

\author{
TÉRCIO JACQUES FEHLAUER², BENEDITA MARIA RODRIGUES-OTUBO ${ }^{3}$ \\ MÁRCIO SANDRINI ${ }^{4}$, DEONISIO DESTRO
}

RESUMO - Este trabalho visou a avaliar o comportamento de quatro genótipos de banana: híbridos FHIA 1, BRS FHIA 18 e as cultivares Caipira e Prata-Anã durante o primeiro ciclo de produção, nas condições edafoclimáticas de Bonito, Mato Grosso do Sul. As maiores produtividades foram observadas para os híbridos FHIA 1 e BRS FHIA 18, com médias de 26,95 e 24,5 t/ha, respectivamente. Os híbridos foram superiores, estatisticamente, para as características massa do cacho (MC), número de pencas (NP), massa da ráquis (MR) e massa total de frutos (MTF). Os híbridos e a cultivar Caipira apresentaram médias semelhantes para número total de frutos (NTF), destacando-se o híbrido BRS FHIA 18 com 119,30. Quanto ao ciclo de produção, o híbrido BRS FHIA 18 e as cultivares apresentaram o mesmo período de floração à colheita (PFC), em média, 142 dias. O híbrido BRS FHIA 18 e 'Prata-Anã' tiveram comportamento mais precoce para o florescimento (NDF), enquanto o híbrido FHIA 1, mais tardio, apresentou menor período do florescimento à colheita (120 dias). Pelos resultados desta avaliação, os híbridos FHIA 1 e BRS FHIA 18 apresentaram melhor produtividade. O híbrido BRS FHIA 18 teve menor ciclo produtivo na região de Bonito-MS. Termos para indexação: Musa spp., cultivares, híbridos, ciclo de produção.

\section{CHARACTERIZATION OF THE PRODUCTION OF BANANA GENOTYPES IN BONITO REGION, STATE OF MATO GOSSO DO SUL}

\begin{abstract}
This work aimed to evaluate the behavior of four banana genotypes: FHIA 1,FHIA 18 hybrids and Caipira and Prata-Anã cultivars during the first production cycle under the environmental conditions of Bonito - MS. The hybrids FHIA 1 and FHIA 18 presented the highest yield with 27 and $24.5 \mathrm{t} / \mathrm{ha}$ respectively. The hybrids were statistically higher when compared with the cultivars for the characters bunch mass, number of hand, raquis mass and total mass of fruits. The hybrids and the Caipira cultivar presented similar mean for total number of fruits, with FHIA 18 presenting the highest mean of 119.30. In relation to the production cycle, the FHIA 18 hybrid and the cultivars showed the same cycle from flowering to harvest (142 days). FHIA 18 hybrid and 'Prata-Anã' presented shorter cycle up to flowering while FHIA 1 hybrid was later, presenting a shorter period from flowering to harvest (120 days). From the results obtained in this evaluation, the hybrids FHIA 1 and FHIA 18 presented larger productivity. The FHIA 18 hybrid had the lower production cycle in Bonito-MS region.
\end{abstract}

Index terms: Musa spp., cultivars, hybrids, production cycle.

A banana é originária do continente asiático e atualmente se encontra distribuída em várias regiões tropicais, sendo considerada uma das frutas há mais tempo consumida no mundo. O Brasil, em 2007, destacou-se como o quarto produtor mundial, com 7,1 milhões de toneladas, em 515,4 mil ha (FAO, 2009), perdendo para a Índia, Uganda e Equador. As maiores produções de banana no Brasil concentramse nas regiões Nordeste e Sudeste, com 2,8 e 2,0 milhões de toneladas (IBGE, 2007), enquanto a região Centro-Oeste, apesar de não se destacar como produtora de banana, apresenta potencial para aumento da área produtiva, contribuindo, assim, para o desenvolvimento socioeconômico e a diversificação agrícola.

Apesar da variedade de cultivares de banana existentes no Brasil, poucas apresentam potencial agronômico para utilização comercial (SILVA et

\footnotetext{
' (Trabalho 031-09) Recebido em: 20-01-2009. Aceito para publicação em: 24-04-2010.

${ }^{2} \mathrm{Eng}^{\circ} \mathrm{Ag}^{\mathrm{o}}$, MSc. Pesquisador, AGRAER, CEP: 79114-000,Campo Grande-MS, e-mail:terciofe@yahoo.com.br

${ }^{3}$ Bióloga MSc., Doutoranda, Pesquisadora AGRAER, CEP: 79114-000, Campo Grande-MS, e- mail:bmrotubo@yahoo.com.br

${ }^{4} \mathrm{Eng}^{\mathrm{O}} \mathrm{Ag}^{\mathrm{o}} \mathrm{MSc}$. ,Pesquisador AGRAER,CEP: 79114-000, Campo Grande-MS, e-mail:marciosandrini@bol.com.br

${ }^{5} \mathrm{Eng}^{\mathrm{o}} \mathrm{Ag}^{\mathrm{o}}$ Dr., Professor, Universidade Estadual de Londrina-UEL, Departamento de Agronomia, C.P. 6001 - CEP $86051-990$ -

Londrina-PR, e-mail:deonisiodestro@yahoo.com
} 
al., 1997), por possuírem baixa produtividade (< $16 \mathrm{t} / \mathrm{ha}$ ), porte elevado e suscetibilidade a pragas e doenças que afetam o bom desempenho da cultura (ALVES, 1986).

O emprego de cultivares resistentes ou tolerantes às principais doenças foliares, como a sigatoka-negra (Mycosphaerella fijiensis) (CORDEIRO et al., 1998a; GASPAROTTO et al., 2006), sigatoka-amarela (Mycosphaerella musicola Leach), o mal-do-panamá (Fusarium oxysporum f.sp. cubense) (Smith, Snyder e Hansen), seria a opção mais viável para a implantação de novos cultivos (MOREIRA, 1997; CORDEIRO et al., 1998b), principalmente em áreas onde se preconiza a preservação ambiental, uma vez que, não utilizando defensivos, não causaria agressão ao meio ambiente e reduziria o custo de produção, assim como a prática da adubação orgânica (SWENNEN; WILSON, 1982; BORGES et al., 2002), pela disponibilidade desse insumo nas propriedades, além de agregar valor ao produto.

A identificação de genótipos potenciais para novas regiões é de suma importância para o desenvolvimento da cultura. Desta forma, três genótipos introduzidos e desenvolvidos pela EMBRAPA como os híbridos: FHIA 1 resistente à Sigatoka negra e Mal do panamá e BRS FHIA 18 (híbrido de 'Prata-Anã' x 2n FHIA) resistente à Sigatoka negra e amarela, a cultivar Caipira resistente à Sigatoka-negra e amarela e Mal-do-Panamá (SILVA et al., 2003; DONATO et al., 2003) e como controle a cultivar Prata-Anã, que embora suscetível a doenças possui maior área plantada no Brasil, além de apresentar grande aceitação pelo mercado interno (LEONEL et al., 2004), foram utilizados neste trabalho, cujo objetivo foi a caracterização da produção, na região de Bonito-MS.

O trabalho foi conduzido na Fazenda Serradinho, município de Bonito, região sudoeste do Estado de MS, tendo como características geográficas: coordenadas de $21^{\circ} 07^{\prime} 16^{\prime \prime}$ de latitude sul e $56^{\circ} 28^{\prime} 55^{\prime}$ " de longitude oeste, com predominância de clima tropical seco. Os dados de precipitação pluviométrica $(\mathrm{mm})$ coletados durante o período experimental encontram-se na Figura 1.

$\mathrm{O}$ experimento foi implantado em área onde predomina o Latossolo Vermelho, classificado como pouco desenvolvido, com textura arenoargilosa, apresentando topografia plana, utilizando-se de mudas procedentes da EMBRAPA.

O plantio foi realizado no mês de setembro de 1997, no espaçamento de 3 x 2 m, e mantido em condições de sequeiro. Foi adotada a adubação recomendada por Borges (1994), compatível com a análise de solo, a qual não indicou correção de pH. Na cova, utilizou-se a adubação orgânica composta de $3 \mathrm{~kg}$ de cama de frango $+150 \mathrm{~g}$ de termofosfato magnesiano, seguida de quatro adubações de cobertura, em gramas/planta, aos $30 ; 90 ; 180$ e 270 dias após o plantio, sendo a primeira com sulfato de amônio ( $80 \mathrm{~g})$ e as seguintes compostas de: sulfato de amônio $(80 \mathrm{~g})$, cloreto de potássio $(100 \mathrm{~g})$ e sulfato de magnésio $(10 \mathrm{~g})$. Os tratos culturais seguiram as recomendações técnicas para a cultura, enquanto o controle de pragas e doenças não foi efetuado.

Utilizou-se o delineamento de blocos ao acaso, com quatro tratamentos (cultivares e híbridos), 6 repetições por tratamento e parcela constituída de 12 plantas. Os tratamentos foram compostos pelos seguintes genótipos: híbridos FHIA 1 e BRS FHIA 18 , cultivar Caipira (grupo AAA) triploide e a cultivar Prata-Anã (grupo AAB) triploide, como controle. Foram avaliados os seguintes parâmetros: massa do cacho $(\mathrm{MC})$, massa da ráquis (MR) e massa total de frutos (MTF) em quilograma, produtividade $(\mathrm{t} /$ ha), número de pencas (NP) e número total de frutos (NTF) referentes à produção e data da floração (NDF), data da colheita (NDC), período da floração à colheita $(\mathrm{PFC})=\mathrm{NDC}-\mathrm{NDF}$, em dias, referente ao primeiro ciclo de produção (11-98 até 04-99). Os dados obtidos foram submetidos à análise de variância, e as médias dos tratamentos, comparadas pelo teste de Tukey, ao nível de 5\% de probabilidade.

As médias observadas para as características massa do cacho, da ráquis, massa total de frutos e número de pencas foram estatisticamente semelhantes entre os híbridos e as cultivares, tendo os híbridos se destacado nas condições avaliadas (Tabela 1). Os híbridos FHIA 1 e BRS FHIA 18 apresentaram médias de massa de cacho de $16,18 \mathrm{~kg}$ e $14,84 \mathrm{~kg}$, respectivamente. Donato et al. (2003) observaram média semelhante para FHIA 18 e inferior para FHIA $1(12,8 \mathrm{~kg})$ no sudoeste da Bahia, utilizando-se de mudas micropropagadas com irrigação, enquanto Ledo et al. (2009) observaram, para FHIA $18 \mathrm{em}$ Sergipe, cachos com 18,42 kg sob irrigação. As cultivares Prata-Anã e Caipira apresentaram médias de 7,01 kg e 7,37 kg, enquanto cachos em torno de $12,0 \mathrm{~kg}$ foram observados para 'Prata-Anã', por Leonel et al. (2004), em Botucatu, e por Donato et al. (2003), em Guanambi, Bahia. Rendimento mais elevado obtiveram Donato et al. (2006) no sudoeste da Bahia, com cachos 50\% acima de $18 \mathrm{~kg}$, durante o primeiro ciclo. A cultivar Caipira obteve cachos com $7,37 \mathrm{~kg}$, em condições não irrigadas, com precipitação média anual de $1.824 \mathrm{~mm}$, distribuídos irregularmente (Figura 1), enquanto cachos acima de $14 \mathrm{~kg}$ foram obtidos por Donato et al. (2003), com 
mudas micropropagadas irrigadas, e por Gomes et al. (2000), no Espírito Santo, em plantios não irrigados e com precipitação média anual de $1.300 \mathrm{~mm}$.

A produção média (Tabela 1) das cultivares em estudo foi baixa, tendo a 'Prata-Anã' alcançado produtividade de 12,27 t/ha e a 'Caipira' de 11,66 t/ ha. Leonel et al. (2004) observaram produtividade de 19,50 t/ha, utilizando mudas micropropagadas e irrigação complementar, na região de Botucatu. Segundo Silva et al. (1997), a cultivar Caipira pode alcançar, sob condições de irrigação, 25 a 30 t/ha/ ciclo, enquanto 'Prata-Anã' 30 a 35 sob as mesmas condições. A baixa produtividade das cultivares observada neste trabalho deve-se provavelmente às condições não irrigadas da condução do experimento e à má distribuição de chuvas (Figura 1), com baixa incidência de chuvas coincidindo com o período de florescimento, aliada à baixa capacidade do solo em compensar eventuais deficiências de adubação, em função da adubação orgânica complementar. $\mathrm{Na}$ Nigéria, trabalhos com bananeiras do subgrupo Terra mostraram produtividades constantes nos ciclos seguintes, quando utilizada a adubação orgânica (SWENNEN; WILSON, 1982). Para Borges et al. (2002), o uso de adubação orgânica complementar (esterco de curral) induziu maior número de frutos por cacho na cultivar Terra, em comparação ao uso de diferentes níveis de nitrogênio.

A produtividade variou entre os grupos genômicos (potencial genético). Melhor desempenho foi observado para os híbridos tetraploides FHIA 1 e BRS FHIA 18 com 26,95 e 24,72 t/ha, respectivamente, em relação às cultivares triploides Prata-Anã e Caipira, nas condições avaliadas (Tabela 1). Rodrigues et al. (2006) obtiveram, para as cultivares Caipira e Prata-Anã, produtividades de 26,30 e 17,16 t/ha, respectivamente, e para os híbridos FHIA 1 e FHIA 18, 34,69 e 29,26, respectivamente, ao norte de Minas. Maior produtividade foi observada na Austrália, em plantios comerciais do genótipo tetraploide 'Goldfinger' (FHIA 1), alterando a densidade de plantio e o arranjo espacial dos tratamentos (LANGDON et al., 2008).

Quanto ao número de pencas (Tabela 1), os híbridos apresentaram médias estatisticamente diferentes das cultivares, variando de 8,50 (BRS FHIA 18) a 7,85 (FHIA 1), enquanto para 'PrataAnã' e 'Caipira' foram observadas médias de 5,97 e 6,25 , respectivamente, ficando abaixo das médias observadas em outras localidades (LEONEL et al., 2004; DONATO et al., 2003; RODRIGUES et al., 2006). Este caráter é considerado de suma importância para o produtor por representar uma unidade comercial (SILVA et al., 2006; LESSA,
2007).

Pela Tabela 1, fica evidenciando a superioridade dos híbridos em relação às cultivares, com massa de fruto maior que o dobro do observado para as cultivares. A 'Prata-Anã' produziu cachos em torno de $7,0 \mathrm{~kg}$, enquanto cachos com massa inferior $(5,85 \mathrm{~kg})$ foi observado por Silva et al. (2002) durante o primeiro ciclo de avaliação.

Quanto ao número total de frutos (Tabela 1), as médias foram estatisticamente semelhantes entre os genótipos, variando de 107,54 ('Caipira') a 119,30 (BRS FHIA 18), enquanto a cultivar PrataAnã apresentou 69,31 frutos por cacho. Número de frutos mais elevados foram obtidos por Rodrigues et al. (2006) para 'Caipira' (181) e 'Prata-Anã' (119 frutos), enquanto os híbridos apresentaram em média 150,5 frutos por cacho, no norte de Minas Gerais. O mesmo comportamento foi observado por Donato et al. (2003), com 158 frutos por cacho para 'Caipira', 107 para 'Prata-Anã', seguido de 124 e 132 para os híbridos FHIA 1 e FHIA 18, respectivamente, no norte da Bahia. O dobro de número de frutos observaram Leonel et al. (2004) e Donato et al. (2006) para 'Prata-Anã', sob condições de irrigação. Estudos realizados com mudas micropropagadas de 'Cavendish-Anã' indicaram que uma produtividade econômica poderá ser obtida se adotado um regime de irrigação no solo variando entre 100 e $85 \%$ de ETm (SHONGWE et al., 2005).

Os genótipos avaliados mostraram a mesma tendência para ciclos vegetativo e reprodutivo, sendo que o híbrido FHIA 1 destacou-se como mais tardio (Tabela 2). Os híbridos tiveram ciclos vegetativos variando de 303,76 (BRS FHIA 18) a 478,75 dias (FHIA 1). O híbrido FHIA 1, de ciclo mais tardio, teve maior produtividade $(26,95 \mathrm{t} / \mathrm{ha})$, provavelmente devido ao estímulo de florescimento ter-se iniciado fora do período de estiagem (Figura 1), enquanto o híbrido BRS FHIA 18, de ciclo mais precoce, teve produtividade de $24,72 \mathrm{t} / \mathrm{ha}$.

O híbrido FHIA 1, com maior ciclo produtivo (598,46 dias), teve menor período do florescimento à colheita (119,71 dias), enquanto o híbrido BRS FHIA 18 , com menor ciclo de produção (445,38 dias), teve período de florescimento à colheita semelhante às demais cultivares ( \pm 143 dias) (Tabela 2$)$. Rodrigues et al. (2006) observaram para os híbridos FHIA 1 e FHIA 18, nas condições do norte de Minas, períodos bem menores e estatisticamente semelhantes do plantio à colheita: 347 dias (FHIA 1) e 344 dias (FHIA 18), e períodos de florescimento à colheita em torno de 120 dias, semelhantes ao observado neste trabalho para o híbrido FHIA 1.

A cultivar Caipira apresentou ciclo de 
produção mais tardio (547,96 dias) e período de florescimento à colheita de 143,86 dias, superior ao observado por Rodrigues et al. (2006) para mudas micropropagadas com irrigação (382 dias) e período de florescimento à colheita de 116 dias. A mesma cultivar, em condições de alta umidade e maior incidência de chuvas, teve ciclos menores de produção e de florescimento à colheita (GOMES et al., 2000).

Para a cultivar Prata-Anã, observou-se um ciclo de 144 dias da floração à colheita e de 470 dias do plantio à colheita. Leonel et al. (2004) obtiveram um ciclo total de 434 dias, utilizando-se de mudas micropropagadas e com irrigação complementar, e Oliveira et al. (2008), 466 dias do plantio à colheita. Ciclos mais reduzidos de florescimento e de produção foram observados no norte de Minas por Rodrigues et al. (2006), com 181 e 320 dias, respectivamente, e no sudoeste da Bahia, por Donato et al. (2006), com 225 e 362 dias, respectivamente, no primeiro ciclo de avaliação.

Pode-se concluir que os híbridos FHIA 1 e BRS FHIA 18 apresentaram melhor produtividade nas condições avaliadas, e o híbrido BRS FHIA 18 teve menor ciclo de produção na região de Bonito.

Agradecemos ao Técnico Agrícola Valder Soares Junior, AGRAER-MS, pelo apoio na condução do experimento e nas avaliações.

TABELA 1 - Massa do cacho (MC), número de penca (NP), massa da ráquis (MR), massa total do fruto (MTF), número total do fruto $(\mathrm{NTF})$ e produtividade (ton/ha), referente à produção durante $\mathrm{o}$ primeiro ciclo, para quatro genótipos de banana. Bonito-MS, 1997-1999.

\begin{tabular}{ccccccc}
\hline Genótipos & MC(kg) & NP & MR(kg) & PTF $(\mathrm{kg})$ & NTF & $\begin{array}{c}\text { Produtividade } \\
\text { (ton/ha) }\end{array}$ \\
\hline FHIA 18 & $14,84 \mathrm{a}^{*}$ & $8,50 \mathrm{a}$ & $1,06 \mathrm{a}$ & $13,63 \mathrm{a}$ & $119,30 \mathrm{a}$ & 24,72 \\
FHIA 1 & $16,18 \mathrm{a}$ & $7,85 \mathrm{a}$ & $1,28 \mathrm{a}$ & $14,86 \mathrm{a}$ & $115,23 \mathrm{a}$ & 26,95 \\
PRATA-ANÃ & $7,01 \mathrm{~b}$ & $5,97 \mathrm{~b}$ & $0,81 \mathrm{~b}$ & $6,18 \mathrm{~b}$ & $69,31 \mathrm{~b}$ & 12,27 \\
CAIPIRA & $7,37 \mathrm{~b}$ & $6,25 \mathrm{~b}$ & $0,74 \mathrm{~b}$ & $6,48 \mathrm{~b}$ & $107,54 \mathrm{a}$ & 11,66 \\
MÉDIA & 11,35 & 7,14 & 0,97 & 10,29 & 102,85 & \\
\hline CV (\%) & 11,63 & 8,04 & 14,17 & 11,02 & 7,39 & \\
\hline
\end{tabular}

* Médias seguidas da mesma letra, nas colunas, não diferem entre si, pelo teste de Tukey, ao nível de $5 \%$ de probabilidade

TABELA 2 - Número de dias do plantio até a floração (NDF), número de dias do plantio até a colheita (NDC), período da floração até a colheita (PFC), referente ao ciclo de produção, de quatro genótipos de banana. Bonito-MS, 1997-1999.

\begin{tabular}{cccc}
\hline GENÓTIPOS & NDF & NDC & PFC \\
\hline FHIA 18 & $303,76 \mathrm{c}^{*}$ & $445,38 \mathrm{c}$ & 141,62 \\
FHIA 1 & $478,75 \mathrm{a}$ & $598,46 \mathrm{a}$ & 119,71 \\
PRATA-ANÃ & $325,98 \mathrm{c}$ & $469,84 \mathrm{c}$ & 143,86 \\
CAIPIRA & $404,29 \mathrm{~b}$ & $547,96 \mathrm{~b}$ & 143,67 \\
MÉDIA & 378,20 & 515,41 & \\
\hline CV (\%) & 5,33 & 3,31 & \\
\hline
\end{tabular}

*Médias seguidas da mesma letra, nas colunas, não diferem entre si, pelo teste de Tukey, ao nível de 5\% de probabilidade. 

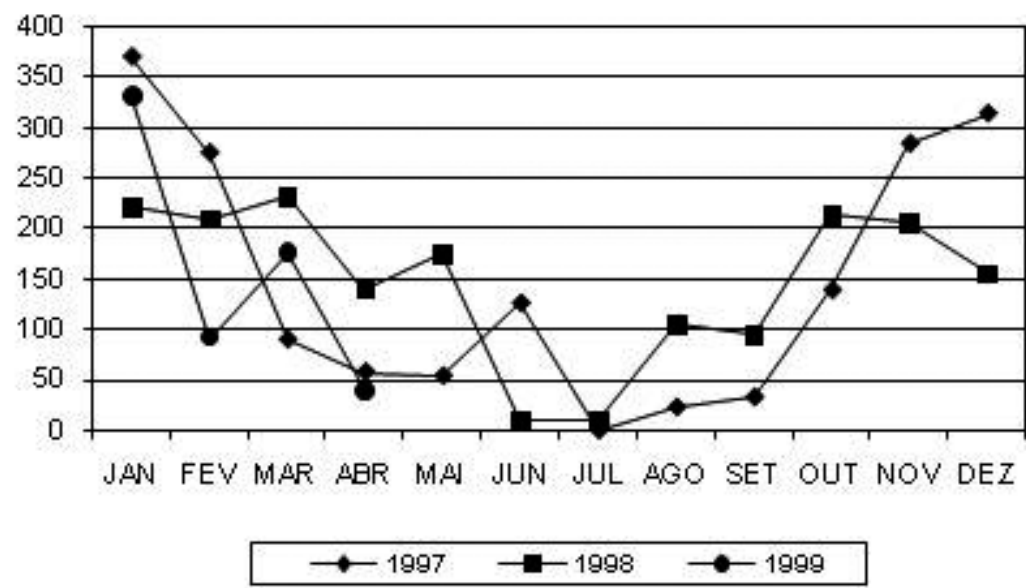

FIGURA 1 - Precipitação pluviométrica ocorrida no período de janeiro de 1997 a abril de 1999, na região de Bonito, MS.

\section{REFERÊNCIAS}

ALVES, E. J. Planejamento, implantação e manutenção de um plantio comercial de banana. Cruz das Almas: Embrapa-CNPMF, 1986.

BORGES, A. L.; SILVA, T. O. da; CALDAS, R. C.; ALMEIDA, I. E. de. Adubação nitrogenada para bananeira-'Terra' (Musa sp. AAB, subgrupo Terra). Revista Brasileira de Fruticultura, Jaboticabal, v.24, n.1, 2002. Disponível em: <http://www.scielo. br/scielo.php?script=sci> . Acesso em: 08 set. 2009.

CORDEIRO, Z. J. M.; MATOS, A. P.; SILVA, S. O. La Sigatoka Negra en Brasil. Tanzânia: INFOMUSA - Revista Internacional sobre Banano y Plátano, Montpellier, v.7, n.1, p.30-31, 1998a.

CORDEIRO, Z. J. M.; SILVA, S. O. PEREIRA, J. C. R., COELHO, A. F. S. Sigatoka negra no Brasil. Informativo SBF, Brasília, v.17, n.2, p.8-10, 1998b.

DONATO, S. L. R.; SILVA, S. de O.; LUCA F ${ }^{\circ}$. O. A.; LIMA, M. B.; DOMINGUES, H.; ALVES, J.da S. Comportamento de variedades e híbridos de banana (Musa spp.), em dois ciclos de produção no sudoeste da Bahia. Revista Brasileira de Fruticultura, Jaboticabal, v.28, n.1, p. 139-144, 2006.
DONATO, S. L. R.; SILVA, S. de O.; PASSOS, A. R.; LIMA NETO, F. P.; LIMA, M. B. Avaliação de variedades e híbridos de bananeira sob irrigação. Revista Brasileira de Fruticultura, Jaboticabal, v. 25 , n. 2, p. 348-351, 2003.

FAO. FOOD AGICULTURAL ORGANIZATION. Disponível em: <http://faostat.fao.org/site/567>. Acesso em: 23 jul. 2009.

GASPAROTTO, L.; PEREIRA, J.C.R.; HANADA, R.E.; MONTARROYOS, A.V.V. Sigatoka-negra da bananeira. Manaus: Embrapa Amazônia Ocidental, 2006. 177 p.

GOMES, J. A.; NÓBREGA, A.C. Comportamento de cultivares e híbridos de bananeira na região produtora do Estado do Espírito Santo. Revista Brasileira de Fruticultura, Jaboticabal, v.22, n. 1, p.11-13, 2000.

IBGE. Produção agrícola municipal. Disponível em: $<$ http://www.sidra.ibge.gov.br $>$, 2007. Acesso em: 12 ago. 2009.

LANGDON, P.W.; WHILEY, A.W.; MAYER, R.J.; PEGG, K.G.; and SMITH, M.K. The influence of planting density on the production of 'Goldfinger' (Musa spp., AAAB) in the subtropics. Scientia Horticulturae, Wageningen, v.115, n.3, p.238-243, 1990. Disponível em: $<$ http://www.sciencedirect. com/science>. Acesso em: 13 set. 2009. 
LEDO, A. S.; SILVA JUNIOR, J. F. da; LEDO, C. A. da S.; SILVA, S. de O. Avaliação de genótipos de bananeira na região do baixo São Francisco, Sergipe. Revista Brasileira de Fruticultura, Jaboticabal, v.30, n.3, p. 691-695, 2008.

LEONEL, S.; GOMES, E. M.; PEDROSO, C. J. Desempenho agronômico de bananeiras micropropagadas em Botucatu-SP. Revista Brasileira de Fruticultura, Jaboticabal, v.26, n.2, p.245-248, 2004.

LESSA, L. S. Avaliação agronômica, seleção simultânea de caracteres múltiplos em híbridos diploides (AA) e desempenho fisiológico de cultivares de bananeira. 2007. 83 f. Dissertação (Mestrado) - Universidade Federal do Recôncavo da Bahia, Cruz das Almas, 2007.

MOREIRA, R. S. Banana: teoria e prática de cultivo. Campinas: Fundação Cargill, 1997. 335p.

OLIVEIRA, T. K. de; LESSA, L. S.; SILVA, S. de O.; Oliveira, J. P. de. Características agronômicas de genótipos de bananeira em três ciclos de produção em Rio Branco-AC. Pesquisa Agropecuária Brasileira, Brasília, v.43, n.8, 2008. Disponível em: <http:// www.scielo.br/scielo.php?script=sci $>$. Acesso em: 16 ago. 2009.

PEREIRA, L. V.; REZENDE e SILVA, C. R. de; ALVARENGA, A. A. Comportamento de cultivares de bananeiras oriundas de mudas de cultura de tecidos e convencionais. In: CONGRESSO BRASILEIRO DE FRUTICULTURA, 15., 1998, Poços de Caldas. Anais... Sociedade Brasileira de Fruticultura e Universidade Federal de Lavras, 1998. p.125.

RODRIGUES, M. G. V.; SOUTO, R. F.; SILVA, S. de O. Avaliação de genótipos de bananeira sob irrigação. Revista Brasileira de Fruticultura, Jaboticabal, v.28, n.3, p. 444-448, 2006.
SILVA, S. de O.; ALVES, E. J.; SHEPHERD, K.; DANTAS, J. L. L. Cultivares. In: ALVES, E. J., org. A cultura da Banana: aspectos técnicos socioeconômicos e agroindustriais. Brasília: Embrapa-SPI, Cruz das Almas: Embrapa-CNPMF, 1997. 885 p.

SILVA, S. de O.; FLORES, J. C. O.; LIMA NETO, F. P. Avaliação de cultivares e híbridos de bananeira em quatro ciclos de produção. Pesquisa Agropecuária Brasileira, Brasília, v.37, p.1567-1574, 2002.

SILVA, S.O. GASPAROTTO, L. MATOS, A.P. CORDEIRO, Z..J.M. FERREIRA, C.F. RAMOS, M.M JESUS, O.N. Programa de melhoramento de bananeira no Brasil: resultados recentes. Cruz das Almas: Embrapa Mandioca e Fruticultura, 2003. $36 \mathrm{p}$.

SILVA, S. de O.; PIRES, E. T.; PESTANA, R. K. N.; ALVES, J. S.; SILVEIRA, D. C. Avaliação de clones de banana Cavendish. Ciência e Agrotecnologia, Lavras, v.30, p.832-837, 2006.

SHONGWE, V. D.; TUMBER, R.; MASARIRAMBI, M. T. and MUTUKUMIRA, N. Soil water requirements of tissue-cultured Dwarf Cavendish banana (Musa spp. L). Scientia Horticulturae, Wageningen, v.106, n.4, p.593-602, 2005. Disponível em: <http://www.sciencedirect.com/science?>. Acesso em: 13 set. 2009.

SWENNEN, R.; WILSON, G.F. Plantain response to organic mulch. Banana Newsletter, Alstonville, n.4, p.10-11, 1982.

TEIXEIRA, L. A. J. Bananeira (Musa spp). In: MELETTI, L.M.M. Propagação de frutíferas tropicais. Guaíba: Agropecuária, 2000. p. 105-124. 